\title{
Evaluation of the Impact of the COVID-19 Lockdown on BMI in Children and Adolescents with or Without Obesity
}

\author{
Albane Bertha Rosa Maggio ( $\sim$ albane.maggio@hcuge.ch ) \\ Hopitaux Universitaires de Geneve https://orcid.org/0000-0002-9110-4467 \\ Claudine Gal-Duding \\ University Hospital Geneva: Hopitaux Universitaires Geneve \\ Xavier Eric Martin \\ University Hospitals Geneva: Hopitaux Universitaires Geneve \\ Catherine Chamay Weber \\ University Hospitals Geneva: Hopitaux Universitaires Geneve
}

\section{Research Article}

Keywords: COVID-19, lockdown, confinement, childhood obesity

Posted Date: February 17th, 2022

DOI: https://doi.org/10.21203/rs.3.rs-783544/v1

License: (a) (i) This work is licensed under a Creative Commons Attribution 4.0 International License.

Read Full License 


\section{Abstract \\ Background}

In Switzerland, from March 15th to May 11th 2020, schools and most shops were closed nationwide due to the COVID-19-related lockdown. This cessation of activities may have impacted weight gain in children and adolescents. The aims of our study were to evaluate the effects of the COVID-19 lockdown on the $\mathrm{BMI}$ of children and adolescents in treatment for obesity, and to compare its evolution to that of the previous year at the same time, as well as to that of normal-weight children.

\section{Methods}

This retrospective study gathered demographic and anthropometric data from subjects aged 2-18 years both with normal weight and with obesity, who attended our hospital clinics at four time points: before and after the lockdown period in 2020, and at the same times of the year in 2019. We used paired t-tests to assess weight, BMI and BMI z-score changes, linear and standard multiple regressions, independent Student's t-tests or Chi-square tests to compare groups, and Pearson correlation coefficient when appropriate.

\section{Results}

Forty-seven children with obesity and 20 normal-weight subjects had complete data for the 4 visits. The mean BMI increased in both groups during the lockdown (obese: $+0.96 \pm 1.5$ vs. control: $+0.51 \pm 0.5$ ), however the increase was significantly more important in the subjects with obesity compared to the same period in 2019 (2019: +0.33 \pm 1.0; mean difference between 2019 and 2020: $+0.63 \pm 2.0 p=0.034$ ).

\section{Conclusion}

The COVID-19 lockdown had a negative impact on the BMI of youth with obesity. Interestingly we observed extreme changes in this population, which was not the case in normal-weight children. Therefore, families with a child with obesity must be actively supported during these stressful and obesogenic periods of confinement.

\section{Background}

The prevalence of childhood obesity reaches $20-25 \%$ in European countries and its treatment has become a great challenge worldwide [11]. All recent studies highlight the multidisciplinary approach necessary to tackle this complex and multifactorial health condition [25; 27]. In 2016, we demonstrated from our cohort that with a specialized multidisciplinary team involving trained doctors, nurses, dieticians, psychologists and physical trainers, we could stabilize and even decrease body mass index 
(BMI) z-score in $80 \%$ cases of children and adolescents with overweight or obesity [3]. However, in our daily practice, we are confronted to ups and downs due to life events that influence weight gain. For instance, we have long since learned that school-related stress (e.g. due to bullying) [14] or summer vacations [9] are punctual risk factors for weight gain in children, as reflected in the literature.

Due to the COVID-19 epidemic that struck the world in 2020, a lockdown has been imposed in Switzerland between March 15th and May 11th 2020. As other obesity specialists $[1 ; 5 ; 22]$, we hypothesized that the closing of schools and sport clubs, as well as the impossibility of having a regular health monitoring at our clinic, would have a negative influence on the weight of our population of children and adolescents with obesity. Studies in children and adults with obesity have reported changes in lifestyle behaviors during the lockdown, but none monitored their weight $[18 ; 19 ; 21 ; 23 ; 29]$. Studies that reported weight gain were based on self-reported weight measurements and no standardized/official measures were used $[19 ; 21]$.

The aims of our study were to evaluate the effects of the COVID-19 lockdown in spring 2020 on the BMI of children treated for obesity in our clinic, and to compare it to the same period in 2019. Finally, we compared their evolution with that of normal-weight children who were followed for other medical reasons during the same periods.

\section{Materials And Methods}

\section{Study design and subjects}

This is a retrospective study, embedded in an ongoing cohort study held at the University Children's Hospital of Geneva.

We analyzed data from two groups of children:

1) Subjects with overweight or obesity (referred to as "subjects with obesity"), aged 2 to 18 years, who attended the obesity clinics in Geneva at two time points in 2019 and in 2020 (4 visits in total): one visit between January 1st and March 15th 2019 and another one between June 1st and August 31st 2019; one visit between January 1st and March 15th 2020 (i.e. before the confinement) and another visit between June 1st and August 31st 2020 (i.e. after confinement).

2) Subjects with normal weight (referred to as "control subjects"), of the same age range, who attended other consultations at the same time points in 2019 and in 2020 (4 visits in total). We analyzed anthropometrics of 20 normal-weight children out of the 69 children who had four visits, after exclusion of 14 subjects without signed consent, 11 toddlers who were younger than our population (<2 years old), 15 underweight (BMI z-Score <-1SD) and 9 overweight or obese children (BMI z-score >+1SD).

In normal circumstances, subjects undergoing treatment for their obesity at our clinic are followed up every one to three months by a doctor or a nurse and, depending on their needs, by a dietician or a 
psychologist. A detailed description of our specialized follow-up can be found in a previous publication [3]. During the COVID lockdown, our consultations were closed and our patients were unable to attend their usual appointments. Control subjects were followed at other clinics, such as: gastroenterology clinic for inflammatory bowel diseases, constipation, gastroesophageal reflux, undetermined chronic stomach ache,...; neurology clinic for epilepsy, febrile convulsion, neurodevelopmental diseases, TDAH,...; pneumology clinic for asthma, fibrosis cystic disease, chronic cough, thorax malformations,...; or immunology clinics. We chose not to include the most severely affected patients whose disease could have had a negative influence on their weight evolution, and thus excluded those who were underweight.

\section{Measures}

\section{Demographics and anthropometrics}

We collected children's age and gender, as well as body weight $(\mathrm{kg})$ in light clothes (panties and tee-shirt) and height $(\mathrm{cm})$ without shoes. Body mass index (BMI) was calculated as weight/height squared $\left(\mathrm{kg} \cdot \mathrm{m}^{-2}\right)$ and z-scores were derived using the World Health Organization references [13]. Underweight was defined as a $\mathrm{BMI} z$-score $<-1 \mathrm{SD}$, normal weight as -1 to $+1 \mathrm{SD}$, overweight as $>+1 \mathrm{SD}$, obesity as $>+2 \mathrm{SD}$ and severe obesity as $>+3 S D$.

\section{Statistical analyses}

\section{Power calculation:}

To calculate the power of our analyses, we used the BMI change and not the BMI z-score, because we observed that the BMI z-score changes were not related to the amplitude of BMI changes when comparing normal-weight and obese subjects. In fact, especially in 2020 , the BMI z-score change was lower in obese children compared to control subjects, despite considerable increase in their BMI. This discrepancy has already been pointed out in other studies that concluded that BMI z-score is inaccurate to track changes in severely obese children and that BMI must be used instead $[2 ; 4 ; 10 ; 17 ; 28]$. That is why we focused our results and discussion on the BMI changes in our study, even if BMI z-scores are presented.

The number of children in each group (subjects with obesity $n=47$, control subjects $n=20$ ) allows the calculation of the effect size of our study. In the group with obesity, with a difference in BMI change of $0.63 \pm 2.0$ between 2019 and 2020 , the effect size was medium (0.558). In the control group, with a difference of $0.05 \pm 0.97$, the effect size was small (0.055). To detect a difference of BMI change of 0.45 \pm 0.35 between obese and control subjects in 2020, the effect size of our study was large (0.997).

\section{Statistical analyses:}

Statistical analyses were performed using the SPSS software 25.0 (Chicago, IL). A descriptive analysis was performed using frequency distributions for the qualitative variables and mean, standard deviation (SD) and range for the quantitative ones (anthropometrics measures). In each group, we looked at the 
evolution of anthropometric data within each year and between 2019 and 2020. Then we compared the evolutions between the two groups. We used paired t-tests to assess weight, BMI and BMI z-score changes, linear and standard multiple regressions, independent Student's t-tests or Chi-square tests to compare groups, and Pearson correlation coefficient when appropriate. The differences were considered as significant if $p<0.05$.

\section{Results}

\section{Subjects with obesity}

\section{Characteristics}

Characteristics of this group of patients are displayed in Table 1. In 2019, $17 \%$ were overweight (BMI zscore $1-2 ; n=9 / 47$ ), $59.6 \%$ were obese (BMI z-score $2-3 ; n=28$ ) and $23.4 \%$ were severely obese (BMI zscore $>3 ; n=11)$. Seventy percent $(n=33 / 47)$ were under the age of 12 in 2019 . 
Table 1

Characteristics of subjects with obesity and normal weight in 2019 and 2020

\section{Subjects with obesity}

Number of subjects:

Gender female: n (\%)

January to March

\begin{tabular}{|c|c|c|c|c|}
\hline & \multicolumn{2}{|c|}{ Subjects with obesity } & \multicolumn{2}{|c|}{ Control subjects } \\
\hline Number of subjects: & 47 & & 20 & \\
\hline Gender female: $\mathrm{n}(\%)$ & $24(51.1)$ & & $6(30.0)$ & \\
\hline \multicolumn{5}{|l|}{ January to March } \\
\hline & 2019 & 2020 & 2019 & 2020 \\
\hline Age: years & $11.2 \pm 2.1$ & $12.2 \pm 2.1$ & $10.1 \pm 3.9$ & $11.1 \pm 3.9$ \\
\hline Age range: years & $6.3-15.5$ & $7.2-16.5$ & $2.9-15.7$ & $3.8-16.7$ \\
\hline Weight: kg & $\begin{array}{l}63.6 \pm \\
15.8\end{array}$ & $71.0 \pm 15.4$ & $34.4 \pm 14.0$ & $37.7 \pm 14.4$ \\
\hline Height: cm & $\begin{array}{l}151.8 \pm \\
11.6\end{array}$ & $157.4 \pm 11.1$ & $138.5 \pm 24.4$ & $143.1 \pm 22.5$ \\
\hline BMl: kg.cm ${ }^{-2}$ & $27.1 \pm 3.7$ & $\begin{array}{l}28.3 \pm 3.5 \\
\delta \delta \delta\end{array}$ & $17.0 \pm 1.8$ & $\begin{array}{l}17.5 \pm \\
2.1^{\delta \delta \delta}\end{array}$ \\
\hline BMI z-score & $2.72 \pm 0.8$ & $2.67 \pm 0.8$ & $-0.08 \pm 0.5$ & $-0.03 \pm 0.5$ \\
\hline \multicolumn{5}{|l|}{ June to August } \\
\hline Time in-between both visits: months & $4.5 \pm 1.5$ & $4.3 \pm 1.3$ & $3.4 \pm 1.1^{\dagger}$ & $3.9 \pm 1.0$ \\
\hline Weight: kg & $\begin{array}{l}66.5 \pm \\
15.9\end{array}$ & $75.2 \pm 16.0$ & $35.9 \pm 15.0$ & $39.7 \pm 14.9$ \\
\hline Height: cm & $\begin{array}{l}154.4 \pm \\
11.4\end{array}$ & $159.5 \pm 11.1$ & $139.5 \pm 24.2$ & $144.8 \pm 22.2$ \\
\hline BMI: kg.cm-2 & $27.5 \pm 3.7$ & $\begin{array}{l}29.2 \pm 4.0 \\
\delta \delta \delta\end{array}$ & $17.5 \pm 2.1$ & $18.1 \pm 2.2^{\delta \delta}$ \\
\hline
\end{tabular}

Results are expressed as mean and SD or range.

Differences of weight gain and BMI during the same year: ${ }^{*} p<0.05$; $* *<0.01$; $* \star * p<0.001$

Differences of BMI, BMI z-scores, weight gain and BMI increase between 2019 and 2020 per group: $\delta$ $\mathrm{p}<0.05 ;{ }^{\delta \delta} \mathrm{p}<0.01 ; \delta \delta \delta \mathrm{p}<0.001$

Differences of time in-between visits, weight gain and BMI increase between obese and controls in 2019: ${ }^{\dagger} p<0.05 ;{ }^{\dagger \dagger} p<0.01 ;{ }^{+t \dagger} p<0.001$

Differences of time in-between visits, weight gain and $\mathrm{BMI}$ increase between obese and controls in 2020: $¥ p<0.05 ; ¥ p<0.01 ; ¥ ¥ p<0.001$

Abbreviations: BMI: body mass index

Control subjects

20

$6(30.0)$

$24(51.1)$

47

Page 6/15 


\begin{tabular}{|c|c|c|c|c|}
\hline \multirow[b]{2}{*}{ BMI z-score } & \multicolumn{2}{|c|}{ Subjects with obesity } & \multicolumn{2}{|c|}{ Control subjects } \\
\hline & $2.6 \pm 0.7$ & $2.72 \pm 0.8$ & $0.07 \pm 0.5$ & $0.14 \pm 0.5$ \\
\hline Weight gain between both visits & $2.9 \pm 2.5$ & $4.2 \pm 4.7^{* \star *}$ & $\begin{array}{l}1.5 \pm 1.6^{* \star *}, \\
+\dagger\end{array}$ & $2.0 \pm 1.6^{* \star *}$ \\
\hline Weight gain: range & $-2.3-8.4$ & $-10.1-18.4$ & $0.2-6.5$ & $0.2-7.0$ \\
\hline Difference of BMI between both visits & $0.33 \pm 1.0$ & $\underset{* \star \star, \delta}{0.6} \pm 1.5$ & $0.46 \pm 0.8^{*}$ & $0.51 \pm 0.5^{\star \star \star}$ \\
\hline $\begin{array}{l}\text { Difference of BMI between both visits: } \\
\text { range }\end{array}$ & $-1.9-3.1$ & $-3.8-6.1$ & $-0.3-2.8$ & $-0.2-2.1$ \\
\hline \multicolumn{5}{|c|}{ Results are expressed as mean and SD or range. } \\
\hline \multicolumn{5}{|c|}{ Differences of weight gain and BMI during the same year: ${ }^{*} p<0.05 ;{ }^{* \star} p<0.01 ; * \star \star p<0.001$} \\
\hline \multicolumn{5}{|c|}{$\begin{array}{l}\text { Differences of BMI, BMI z-scores, weight gain and BMI increase between } 2019 \text { and } 2020 \text { per group: } \delta \\
p<0.05 ;{ }^{\delta} p<0.01 ;{ }^{\delta \delta \delta} p<0.001\end{array}$} \\
\hline \multicolumn{5}{|c|}{$\begin{array}{l}\text { Differences of time in-between visits, weight gain and BMI increase between obese and controls in } \\
\text { 2019: }{ }^{\dagger} p<0.05 ;{ }^{++} p<0.01 ;{ }^{++} p<0.001\end{array}$} \\
\hline \multicolumn{5}{|c|}{$\begin{array}{l}\text { Differences of time in-between visits, weight gain and BMI increase between obese and controls in } \\
\text { 2020: }{ }^{¥} p<0.05 ; ¥ p<0.01 ; ¥ ¥ p<0.001\end{array}$} \\
\hline Abbreviations: BMI: body mass index & & & & \\
\hline
\end{tabular}

\section{Evolution between pre and post-lockdown periods}

In 2019, children and adolescents gained almost 3 kilos in the 4-month period, while in 2020 weight gain exceeded 4 kilos during the 4-month lockdown. However, the difference was not significant when comparing 2019 and 2020 ( $p=0.126)$. We examined the characteristics of the 5 children who lost or gained the most weight. The 5 patients who lost the most weight were older than the rest of the subjects (lost weight: $14 \pm 1.7$ years old vs. others: $11.9 \pm 2.1 ; p=0.035$ ). Furthermore, the time between the two visits was longer for the 5 children who gained the most weight compared to the rest of the subjects ( 6.0 \pm 0.7 months vs. others: $4.1 \pm 1.3 ; p=0.002$ ). There was no difference either in gender repartition or baseline BMI.

As expected, the BMI increased significantly both in 2019 and in 2020 (2019: $p=0.023 ; 2020: p<0.001)$. While the increase was of the expected magnitude in 2019 after a 4-month period $\left(\mathrm{BMl}+0.33 \mathrm{~kg} / \mathrm{m}^{2}\right)$, it was significantly greater in 2020, with a difference between the 2 years of $+0.63 \pm 2.0, p=0.034$; Fig. 1 . Figure 2 shows the difference of BMI changes between 2019 and 2020 according to the age category. 
Although the difference between age categories was not significant, the graph shows a wide range of changes in adolescents with obesity.

When looking at the BMI z-score, it remained stable between the pre and post-lockdown periods both years (2019: $-0.05 \pm 0.2, p=0.099 ; 2020: 0.05 \pm 0.2, p=0.145$ ) but was significantly higher in 2020 compared to $2019(+0.1 \pm 0.34, p=0.045)$.

There were no correlations between weight, $\mathrm{BMI}$ or BMI z-score evolutions and gender, age or age categories ( $</>12$ years) in either 2019 or 2020 .

\section{Control subjects}

\section{Characteristics}

Characteristics of subjects are provided in Table 1. Sixty-five percent $(n=13 / 20)$ were under the age of 12 in 2019 and there were more boys than girls.

\section{Evolution between pre and post-lockdown periods}

Normal-weight children gained only 1.5 kilos during the studied period in 2019 and 2 kilos during the lockdown in 2020. The difference was not significant $(p=0.331)$. We also looked at the characteristics of the 5 children who gained or lost the most weight. There was no difference in age, gender or baseline BMI.

As expected, control subjects increased significantly their BMI both in 2019 and in 2020 (2019: $p=0.025$; 2020: $p<0.001$; Fig. 1), but the magnitude of the increase was similar between 2019 and $2020(p=$ 0.805). Figure 2 shows the difference of BMI change between 2019 and 2020 according to the age category, which was not significant.

Control subjects' BMI z-scores increased in $2020(+0.17 \pm 0.2, p=0.003)$, while it was stable in $2019(+$ $0.15 \pm 0.4, p=0.094)$.

There was no correlation between weight, BMI or BMI z-score evolutions and gender, age or age categories ( $</>12$ years) in either 2019 or 2020.

\section{Comparison between subjects with obesity and control subjects}

Mean age, repartition in age categories and gender were comparable between groups $(p=0.234, p=$ $0.0674, p=0.113$; respectively). The time between the two visits was shorter for the control group in 2019 $(p=0.002)$, but equal in $2020(p=0.154)$. Weight gains in 2019 and in 2020 were more important in the subjects with obesity compared to the control group $(2019$ : $+1.4 \pm 0.6, p=0.01 ; 2020:+2.2 \pm 0.8, p=$ $0.006)$, even after adjustment for the time between both visits. 
As the subjects with obesity also increased their height more than the controls even after adjustment for age, the BMI evolution was similar between the 2 groups either in 2019 or in 2020, but the difference almost reached statistical significance in $2020(p=0.613 ; p=0.079)$. Furthermore, the difference in BMI evolution between 2019 and 2020 was not significant when comparing the 2 groups, even if subjects with obesity seemed to have increased their BMI more in 2020 than in 2019 (subjects with obesity: $+0.63 \pm 2.0$ vs. control subjects: $+0.05 \pm 1.0 ; p=0.113$ ).

\section{Discussion}

The purpose of this retrospective study was to investigate the effects of the COVID-19 lockdown on BMI on youth with and without obesity.

Indeed, several studies demonstrated that the 2020 lockdown resulted in behavioral and lifestyle changes, especially related to dietary choices and habits as well as in sedentary and physically active occupations $[19 ; 21]$. Subjects with obesity seemed particularly at risk since some studies showed that those changes have caused a weight gain of 1.5 to 3 kilos in adults suffering from excess weight [18; 23; 29], a phenomenon that some authors have called "covibesity" [15]. However, to date, no studies have looked at this issue in children. Therefore the aim of our study was to look at the weight evolution during the lockdown period in children and adolescents with obesity regularly followed in our consultation, and to compare the evolution to the same period the previous year. We were also interested to see if normalweight children followed for other medical reasons experienced the same difficulties as our population.

Normal growth during childhood involves weight gain and height increase, with an average increase of the BMI of 0.3 points every 3 months. In our study, although we did observe a gain in weight and BMI during the 2 studied periods both in normal-weight youth and in those with obesity, the increase was not of the same magnitude between the two groups.

Indeed, during almost a similar interval, subjects with obesity gained twice as much weight as normalweight subjects, whether it be in 2019 or in 2020. This difference may be explained by several factors. First, this finding may simply confirm the tendency of subjects with obesity to gain more weight than normal-weight children, as suggested by Lagstöm et al. [16]. However, in our study, subjects with obesity were one year older and it is possible that some of them were further along in the puberty process, as might suggest the fact that they grew significantly more (height $+2 \mathrm{~cm}$ vs. +1 in the control subjects), even after age adjustment. However, since no puberty outcomes were assessed, we can only assume this. Nevertheless, weight gain was more pronounced in the subjects with obesity during the 2020 lockdown period and between 2019 and 2020 with a difference of 1.3 kilo, against a difference of only 0.5 kilo in the control group. This difference in weight gain between normal-weight and obese subjects during the lockdown has been already observed in adult studies, with almost identical magnitude of weight gain between the 2 groups as we observed in our study [8;18]. Similarly, while the BMI increased in both groups in 2019, this increase was more pronounced during the lockdown in 2020 for children with obesity. The difference of BMI between 2019 and 2020 was of 0.6 points in subjects with obesity 
compared to only 0.05 points in the control group. It is interesting to note that in 2019 , even if the difference was not statistically significant, the BMI change seemed to be smaller in the obese than in the control subjects. This may confirm the positive impact of specific support for children with obesity, as suggested in other publications $[6 ; 24 ; 30]$. Furthermore, our results also suggest that it may be more difficult for children and families dealing with weight concerns to maintain their efforts when the environment and living conditions change drastically, such as during the lockdown we experienced in 2020 , especially when no medical follow-up can be provided, as was the case in our hospital.

Another interesting result related to the weight range or BMI changes of in our study was that subjects with obesity tended to display more extreme changes than controls, especially in 2020 . Some patients took advantage of this special circumstance to improve their diet and spend more time exercising, losing as much as 10 kilos, while others were unable to stick to our recommendation, gaining up to 18 kilos of weight. This may reflect the difficulties encountered by our population suffering from obesity to regulate their weight. The subjects who lost the most weight were older than the others and one explanation could be that adolescents no longer had the possibility to buy fatty and sugary foods after school or during their lunch break. Not surprisingly, the ones who put on the most weight had a longer interval between medical visits. This can have several explanations. First, it is known that motivation lasts only a few weeks and that it may be difficult to maintain an effort when medical appointments are as far apart as 6 months. Secondly, children who knew they had gained weight might have delayed their visit after the end of lockdown in an attempt to stabilize their weight before their next appointment. They might also have been afraid of catching the COVID-19 disease on their way to the hospital using public transports or during their medical visit. Stress being generally recognized as a risk factor related to excessive weight [12], it is possible that anxious patients were negatively impacted by pandemic-related stress, which might have caused, among other consequences, eating disorders to appear or worsen $[7 ; 20 ; 26]$. Normalweight children did not show such extreme changes, as they probably struggled less with food choices or quantities and were more prone to move even when their usual physical activities were cancelled.

This study has some limitations. First, the sample size is small and we could probably have seen a more significant difference between the groups if it had been larger. However, to date, no other study has actually measured and compared weight as precisely at two years interval. Secondly, we did not look at the relationship between weight and lifestyle changes in the present study, however, we investigated this outcome in a group of adolescents in different study which results will be published soon (manuscript submitted). Finally, the normal-weight group was composed of children with medical health conditions and not healthy ones, which may have influenced their weight evolution. However, this bias was minimized when we compared 2019 to 2020 in the same children. Furthermore, we excluded underweight children to ensure that seriously ill patients were not included in the sample and we controlled the normal staturo-weight evolution of the selected subjects to make certain that their disease had no significant impact on it. Besides, the vast majority of our subjects were suffering from minor afflictions such as chronic cough, reflux or constipation, conditions on which the lockdown would not have had much influence. 


\section{Conclusion}

The COVID-19 lockdown is known to have a negative impact on lifestyle behaviors and our study confirmed an excessive weight gain in children and adolescents with obesity. Furthermore, changes were more polarized in both weight gain and weight loss in this population, which demonstrates the complexity of obesity management. Therefore, families with an overweight or obese child or adolescent must be more actively supported during this stressful and obesogenic times when all their bearings have been disrupted.

\section{Declarations}

Ethics Approval and Consent to Participate: The Cantonal Ethics Committee (CCER) approved the study (CCER 2021-01045) and a written informed consent was obtained from all parents of children followed at our obesity clinic. For all the other children, we analyzed the data of those who had signed the Hospital general research consent form. All procedures performed in studies involving human participants were in accordance with the ethical standards of the institutional and/or national research committee and with the 1964 Helsinki declaration and its later amendments or comparable ethical standards. This article does not contain any studies with animals performed by any of the authors.

Consent for publication: Written informed consent was obtained from all individual participants included in the study.

Availability of data and material: The datasets used and/or analyzed during the current study are available from the corresponding author on request.

Competing Interests: All the authors declare that he/she has no conflict of interest.

Funding: No funding.

\section{Authors' contributions:}

AM: Dr. M conceptualized and designed the study, drafted and carried out the initial manuscript, and approved the final manuscript as submitted.

CG-D: Ms. G-D coordinated and supervised data collection, critically reviewed the manuscript, and approved the final manuscript as submitted.

XM: Mr. M coordinated and supervised data collection, critically reviewed the manuscript, and approved the final manuscript as submitted.

CCW: Dr. C-W drafted and carried out the initial manuscript, and approved the final manuscript as submitted. 
All authors approved the final manuscript as submitted and agree to be accountable for all aspects of the work

Acknowledgements: Not applicable

\section{References}

1. Balanza-Martinez V, Atienza-Carbonell B, Kapczinski F, De Boni RB. Lifestyle behaviours during the COVID-19 - time to connect. Acta Psychiatr Scand. 2020;141:399-400.

2. Berkey CS, Colditz GA. Adiposity in adolescents: change in actual BMI works better than change in BMI z score for longitudinal studies. Ann Epidemiol. 2007;17:44-50.

3. Chamay-Weber C, Farpour-Lambert NJ, Saunders Gasser C, Martin XE, Gal C, Maggio AB. Obesity Management in Adolescents: Comparison of a Low-Intensity Face-to-Face Therapy Provided by a Trained Paediatrician with an Intensive Multidisciplinary Group Therapy. Obes Facts. 2016;9:112-20.

4. Cole TJ, Faith MS, Pietrobelli A, Heo M. What is the best measure of adiposity change in growing children: BMI, BMI \%, BMI z-score or BMI centile? Eur J Clin Nutr. 2005;59:419-25.

5. Cuschieri S, Grech S. (2020) COVID-19: a one-way ticket to a global childhood obesity crisis? J Diabetes Metab Disord:1-4.

6. Doak CM, Visscher TL, Renders CM, Seidell JC. The prevention of overweight and obesity in children and adolescents: a review of interventions and programmes. Obes Rev. 2006;7:111-36.

7. Fernandez-Aranda F, Casas M, Claes L, Bryan DC, Favaro A, Granero R, Gudiol C, Jimenez-Murcia S, Karwautz A, Le Grange D, Menchon JM, Tchanturia K, Treasure J. COVID-19 and implications for eating disorders. Eur Eat Disord Rev. 2020;28:239-45.

8. Flanagan EW, Beyl RA, Fearnbach SN, Altazan AD, Martin CK, Redman LM. The Impact of COVID-19 Stay-At-Home Orders on Health Behaviors in Adults. Obesity (Silver Spring). 2021;29:438-45.

9. Franckle R, Adler R, Davison K. Accelerated weight gain among children during summer versus school year and related racial/ethnic disparities: a systematic review. Prev Chronic Dis. 2014;11:E101.

10. Freedman DS, Berenson GS. (2017) Tracking of BMI z Scores for Severe Obesity. Pediatrics 140.

11. Garrido-Miguel M, Cavero-Redondo I, Alvarez-Bueno C, Rodriguez-Artalejo F, Moreno LA, Ruiz JR, Ahrens W, Martinez-Vizcaino V. (2019) Prevalence and Trends of Overweight and Obesity in European Children From 1999 to 2016: A Systematic Review and Meta-analysis. JAMA Pediatr:e192430.

12. Groesz LM, McCoy S, Carl J, Saslow L, Stewart J, Adler N, Laraia B, Epel E. What is eating you? Stress and the drive to eat. Appetite. 2012;58:717-21.

13. Group WHOMGRS. WHO Child Growth Standards based on length/height, weight and age. Acta Paediatr Suppl. 2006;450:76-85.

14. Janssen I, Craig WM, Boyce WF, Pickett W. Associations between overweight and obesity with bullying behaviors in school-aged children. Pediatrics. 2004;113:1187-94. 
15. Khan MA, Moverley Smith JE. "Covibesity," a new pandemic. Obesity medicine. 2020;19:100282.

16. Lagström H, Hakanen M, Niinikoski H, Viikari J, Rönnemaa T, Saarinen M, Pahkala K, Simell O. Growth patterns and obesity development in overweight or normal-weight 13-year-old adolescents: the STRIP study. Pediatrics. 2008;122:e876-83.

17. Paluch RA, Epstein LH, Roemmich JN. Comparison of methods to evaluate changes in relative body mass index in pediatric weight control. American journal of human biology: the official journal of the Human Biology Council. 2007;19:487-94.

18. Pellegrini M, Ponzo V, Rosato R, Scumaci E, Goitre I, Benso A, Belcastro S, Crespi C, De Michieli F, Ghigo E, Broglio F, Bo S. (2020) Changes in Weight and Nutritional Habits in Adults with Obesity during the "Lockdown" Period Caused by the COVID-19 Virus Emergency. Nutrients 12.

19. Pietrobelli A, Pecoraro L, Ferruzzi A, Heo M, Faith M, Zoller T, Antoniazzi F, Piacentini G, Fearnbach SN, Heymsfield SB. Effects of COVID-19 Lockdown on Lifestyle Behaviors in Children with Obesity Living in Verona, Italy: A Longitudinal Study. Obesity (Silver Spring). 2020;28:1382-5.

20. Rantala MJ, Luoto S, Krama T, Krams I. Eating Disorders: An Evolutionary Psychoneuroimmunological Approach. Front Psychol. 2019;10:2200.

21. Ruiz-Roso MB, Knott-Torcal C, Matilla-Escalante DC, Garcimartin A, Sampedro-Nunez MA, Davalos A, Marazuela M. (2020) COVID-19 Lockdown and Changes of the Dietary Pattern and Physical Activity Habits in a Cohort of Patients with Type 2 Diabetes Mellitus. Nutrients 12.

22. Rundle AG, Park Y, Herbstman JB, Kinsey EW, Wang YC. COVID-19-Related School Closings and Risk of Weight Gain Among Children. Obesity (Silver Spring). 2020;28:1008-9.

23. Sidor A, Rzymski P. (2020) Dietary Choices and Habits during COVID-19 Lockdown: Experience from Poland. Nutrients 12.

24. Snethen JA, Broome ME, Cashin SE. Effective weight loss for overweight children: a meta-analysis of intervention studies. J Pediatr Nurs. 2006;21:45-56.

25. Styne DM, Arslanian SA, Connor EL, Farooqi IS, Murad MH, Silverstein JH, Yanovski JA. Pediatric Obesity-Assessment, Treatment, and Prevention: An Endocrine Society Clinical Practice Guideline. J Clin Endocrinol Metab. 2017;102:709-57.

26. Termorshuizen JD, Watson HJ, Thornton LM, Borg S, Flatt RE, MacDermod CM, Harper LE, van Furth EF, Peat CM, Bulik CM. Early impact of COVID-19 on individuals with self-reported eating disorders: A survey of 1,000 individuals in the United States and the Netherlands. Int J Eat Disord. 2020;53:1780-90.

27. Thury C, de Matos CV. (2015) Prevention of childhood obesity: a review of the current guidelines and supporting evidence. South Dakota medicine: the journal of the South Dakota State Medical Association Spec No:18-23.

28. Woo JG. Using body mass index Z-score among severely obese adolescents: a cautionary note. International journal of pediatric obesity: IJPO : an official journal of the International Association for the Study of Obesity. 2009;4:405-10. 
29. Yang S, Guo B, Ao L, Yang C, Zhang L, Zhou J, Jia P. Obesity and activity patterns before and during COVID-19 lockdown among youths in China. Clin Obes. 2020;10:e12416.

30. Young KM, Northern JJ, Lister KM, Drummond JA, O'Brien WH. A meta-analysis of family-behavioral weight-loss treatments for children. Clin Psychol Rev. 2007;27:240-9.

\section{Figures}

\section{BMI evolution}

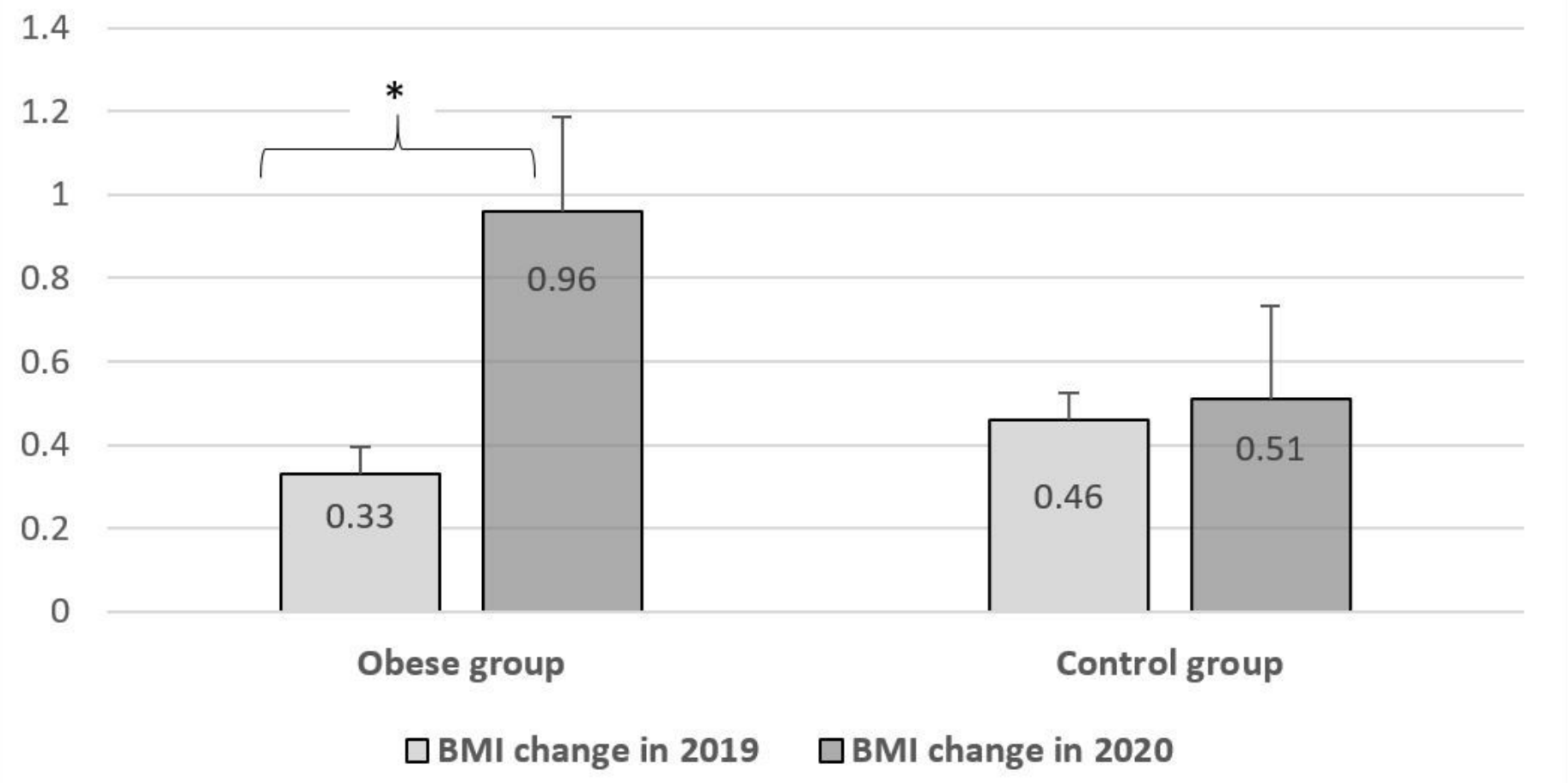

Figure 1

Comparisons of BMI changes between 2019 and 2020 


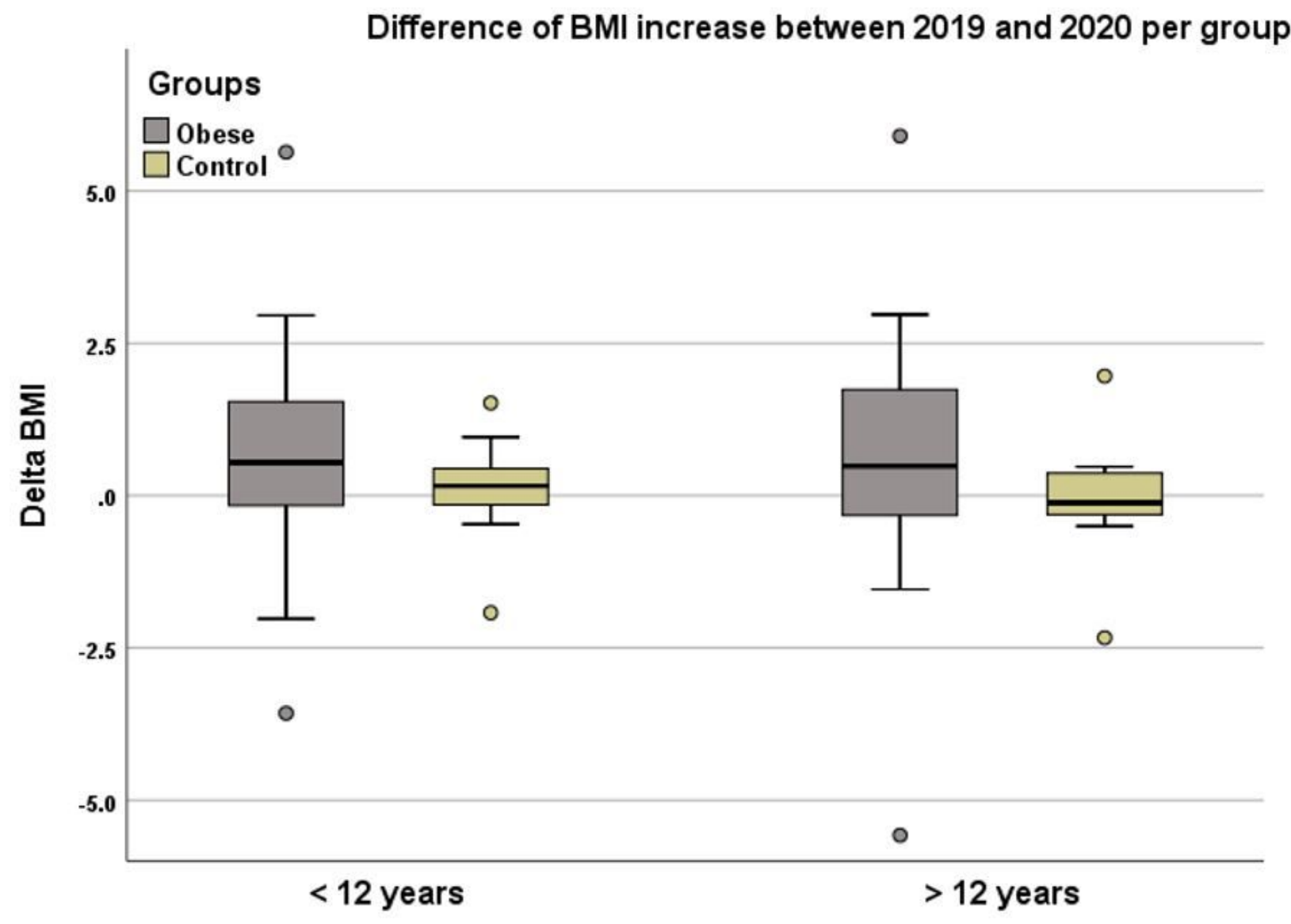

Age categories

Figure 2

Difference in BMl evolution per groups between 2019 and 2020 according to age categories 